\title{
THERMAL EXPANSION EFFECT ON HEAT TRANSFER PROCESSES IN ORIENTATIONALLY-ORDERED MOLECULAR CRYSTALS
}

\author{
O. I. Pursky ${ }^{1}$, V. A. Konstantinov ${ }^{2}$ \\ ${ }^{1}$ Taras Shevchenko Kyiv National University, Department of Physics, \\ 2, Academician Glushkov Ave., Kyiv, UA-03680, Ukraine \\ ${ }^{2}$ B. Verkin Institute for Low Temperature Physics and Engineering, National Academy of Science of Ukraine, \\ 47, Lenin Ave., Kharkiv, UA-61103, Ukraine \\ (Received July 15, 2008; received in final form July 1, 2009)
}

\begin{abstract}
The influence of the thermal expansion on heat transfer processes has been considered in orientationally ordered molecular crystals. A modified method of reduced coordinates was used to separate phonon-phonon and phonon-rotational contributions to the total thermal resistance in isobaric and isochoric cases. It was shown that a discrepancy between temperature dependences of the isobaric $\left(\Lambda_{\mathrm{p}}\right)$ and isochoric $\left(\Lambda_{\mathrm{v}}\right)$ thermal conductivity is mainly governed by the intensity of a phonon-phonon interaction because the phonon-rotational component of thermal resistance weakly depends on thermal expansion.
\end{abstract}

Key words: thermal resistance, thermal expansion, phonon-phonon and phonon-rotation scattering.

PACS number(s): 66.70.+f; 63.20.Ls

\section{INTRODUCTION}

It is commonly supposed that in high-temperature region, at $T \geq \Theta_{D}\left(\Theta_{D}\right.$ is the Debye temperature), the lattice thermal conductivity of dielectric crystals should be inversely proportional to temperature: $\Lambda \propto$ $1 / T$ [1]. For the $1 / T$-dependence to be valid, it is necessary that the crystal volume remain constant; otherwise, vibrational modes would change, which would result in a different temperature dependence of thermal conductivity. The results of numerous experimental studies of thermal conductivity demonstrate considerable deviations from the above dependence [2-7]. In particular, the high-temperature thermal conductivity of orientationally-ordered (OO) molecular crystals decreases with temperature growth by the dependence $\Lambda \propto T^{-n}$, where $n<1-$ in the isochoric case, and $1<n<2-$ at constant pressure. In OO phases of molecular crystals, the distinctions between $\Lambda_{\mathrm{v}}$, and $\Lambda_{\mathrm{p}}$, are associated mainly with the thermal expansion effects.

In the present study, an attempt has been made to find a thermal expansion effect on heat transfer processes in OO molecular crystals.

\section{RESULTS AND DISCUSSION}

Molecular crystals in comparison with atomic substances are characterized by both translational and orientational degrees of freedom. Depending on a specific substance and temperature, the character of orientational molecular motion can vary from low-frequency librations to a nearly free rotation. Such features of the orientational subsystem manifest themselves in thermal properties of molecular crystals. It was shown earlier that the change-over of molecular motion to a weakly hindered rotation in the OO phases of molecular crystals is accompanied by an increase of isochoric thermal conductivity [2]. The transition to a weakly hindered rotation can occur in crystals formed from highly symmetric molecules with a low-energy barrier hampering rotation. As for the crystals formed from low-symmetry molecules, the noncentral interaction forces are considerable, and the orientational order in such crystals is conserved, as a rule, even to melting temperature. In particular, according to the structural data $[8,9]$, the solid $\mathrm{CHCl}_{3}, \mathrm{CH}_{2} \mathrm{Cl}_{2}$, and $\mathrm{CF}_{2} \mathrm{Cl}_{2}$ remain to be orientationally ordered (the corresponding reorientation frequencies do not exceed $10^{4} \mathrm{~s}^{-1}$ ) until the relevant melting temperature is reached.

An important feature of simple molecular crystals is that in condensed phases the intramolecular frequencies (of about $1000 \mathrm{~cm}^{-1}$ ) exceed by an order of magnitude the intermolecular ones (of below $100 \mathrm{~cm}^{-1}$ ), so they can be treated independently. Therefore, from the viewpoint of how different forms of molecular thermal motion affect the heat transfer processes, the translational and rotational molecular motion must be taken into account. In the general case, translational and orientational vibrations are not independent of one another, and propagate through molecular crystals in the form of coupled translational-orientational modes. A direct separation of the contributions by translational and rotational modes to thermal conductivity is rather an involved problem. Therefore, a simplified approach, where the translational and orientational subsystems are considered independently, is often used in practice. In so doing, it is suggested that translational-orientational interaction results in a renormalization of the dispersion law. In this approximation, orientational vibrations of molecules induce an additional thermal resistance [1]. 


\begin{tabular}{|c|c|c|c|c|c|}
\hline Substances & $T_{\mathrm{mol}}, \mathrm{K}$ & $V_{\mathrm{mol}}, \mathrm{cm}^{3} / \mathrm{mole}$ & $\mu, \mathrm{g} / \mathrm{mole}$ & $\sigma, 10^{-8} \mathrm{~cm}$ & $W_{\mathrm{mol}}, m \cdot K / W$ \\
\hline \hline $\mathrm{Kr}$ & 209.4 & 92.01 & 83.8 & 5.34 & 8.06 \\
\hline $\mathrm{Xe}$ & 289.7 & 119.4 & 131.3 & 5.83 & 10.01 \\
\hline $\mathrm{CHCl}_{3}$ & 536.6 & 238.8 & 119.39 & 7.34 & 10.9 \\
\hline $\mathrm{CH}_{2} \mathrm{Cl}_{2}$ & 510 & 181.1 & 81.9 & 6.69 & 8.16 \\
\hline $\mathrm{CF}_{2} \mathrm{Cl}_{2}$ & 384.6 & 218 & 120.9 & 7.13 & 12.7 \\
\hline
\end{tabular}

Table 1. Reduction parameters used at calculations.

Discrepancies in the behaviour of temperature dependences of $\Lambda_{\mathrm{p}}$ and $\Lambda_{\mathrm{v}}$ are connected with thermal expansion of specimens under investigation in the isobaric case. To estimate the influence of thermal expansion on the heat transfer in the OO phases of molecular crystals, in the present investigation we have undertaken to separate the phonon-phonon and phonon-rotation contributions to the total thermal resistance of solid $\mathrm{CHCl}_{3}, \mathrm{CH}_{2} \mathrm{Cl}_{2}$, and $\mathrm{CF}_{2} \mathrm{Cl}_{2}$, in both the isobaric and isochoric cases. Here, it was assumed that the heat is transferred mainly by translational vibrations, irrespective of the degree of orientational ordering, since in orientationally-ordered phases the role of librations in heat transfer turns out to be insignificant on account of a small dispersion of librational branches.

Under the assumption that the contributions of phonon-phonon $W_{\mathrm{pp}}$ and phonon-rotation $W_{\mathrm{pr}}$ interactions to the total thermal resistance $1 / \Lambda=W$ are additive, we separate the phonon-rotation component. For calculations, we used a modified method of reduced coordinates [2]. It is important to note that, in this case, there is no need to resort to some approximation model or other. Suggesting that the total thermal resistance $W$ of $\mathrm{OO}$ molecular crystals is the sum of the phonon-phonon $W_{\mathrm{pp}}$ and phonon-rotational $W_{\mathrm{pr}}$ contributions and that in the reduced coordinates $\left(W^{*}=W / W_{\mathrm{mol}}, T^{*}=T / T_{\mathrm{mol}}\right)$ the component due to the phonon-phonon scattering, is the same as in rare gas solids [10] at equal values of the reduced volume $V^{*}=V / V_{\mathrm{mol}}$, one can extract the phononphonon $W_{\mathrm{pp}}$, and phonon-rotational $W_{\mathrm{pr}}$, components of thermal resistance. As a rule, the reduction parameters are $T_{\text {mol }}=\varepsilon / k_{\mathrm{B}}, \Lambda_{\mathrm{mol}}=\mathrm{k}_{\mathrm{B}} / \sigma^{2} \sqrt{\varepsilon / \mu}$, and $V_{\mathrm{mol}}=N \sigma^{3}$, where $\sigma$ and $\varepsilon$ are the parameters of Lennard-Jones potential, $\mu$ is the molar weight, and $N$ is the total number of particles.

Here, as the reducing parameters $T_{\text {mol }}$ and $V_{\text {mol }}$ we used the values of the temperatures $T_{\mathrm{cr}}$ and molar volumes $V_{\text {cr }}$ of $\mathrm{CHCl}_{3}, \mathrm{CH}_{2} \mathrm{Cl}_{2}$, and $\mathrm{CF}_{2} \mathrm{Cl}_{2}$ and solidified inert gases $\mathrm{Kr}$ and $\mathrm{Xe}$ at their critical points [11] (see Table 1). The choice of the given parameters is explained by the fact that, in the case of simple molecular substances, the critical parameters $T_{\text {cr }}$ and $V_{\text {cr }}$ are proportional to $\varepsilon$ and $\sigma^{3}$, respectively. However, the accuracy of determination is much higher for the critical parameters than for the parameters of a binomial potential. We note that the quantities $\sigma$ and $\varepsilon$ depend essentially on the choice of a binomial potential and the method used to determine it.
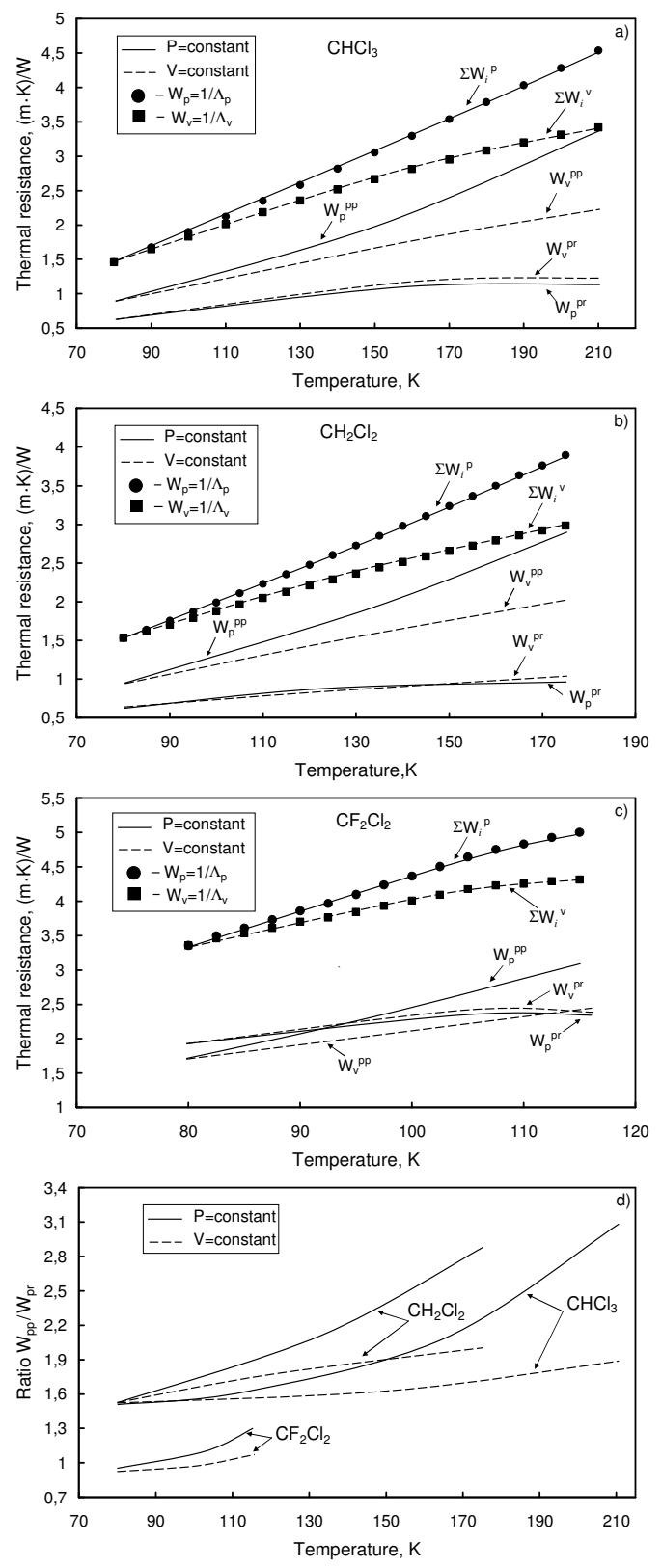

Fig. 1. Phonon-phonon $W_{\mathrm{pp}}$ and phonon-rotational $W_{\mathrm{pr}}$ components of the total thermal resistance $W$ of solid a) $\mathrm{CHCl}_{3}$, b) $\mathrm{CH}_{2} \mathrm{Cl}_{2}$, and c) $\mathrm{CF}_{2} \mathrm{Cl}_{2}$, calculated for the isochoric and isobaric cases. d) Temperature dependences of the ratio $W_{\mathrm{pp}} / W_{\mathrm{pr}}$. 
The results of calculations are presented in Fig. 1. Note that the phonon-phonon component of the thermal resistance is practically independent (within the limits of $2-3 \%$ ) of the choice of rare gas used for comparison. The needed for calculation values of isobaric thermal resistance $W_{\mathrm{p}}=1 / \Lambda_{\mathrm{p}}$ and thermal resistance $W_{\mathrm{v}}=1 / \Lambda_{\mathrm{v}}$ of solid $\mathrm{CHCl}_{3}, \mathrm{CH}_{2} \mathrm{Cl}_{2}$, and $\mathrm{CF}_{2} \mathrm{Cl}_{2}$, at constant volumes $59.5 \mathrm{~cm}^{3} /$ mole, $47.11 \mathrm{~cm}^{3} /$ mole, and $59.1 \mathrm{~cm}^{3} /$ mole, respectively, (which are occupied by the samples of substances at $80 \mathrm{~K}$ ), were taken from [12-14].

As temperature grows the components of the total thermal resistance increase, irrespective of experimental conditions. For all the investigated substances, the values of the phonon-phonon, $W_{\mathrm{p}}^{\mathrm{pp}}$, components of the total thermal resistance at constant pressure exceed the corresponding isochoric values $W_{\mathrm{v}}^{\mathrm{pp}}$. At pre-melting temperatures, the ratio between the $W_{\mathrm{p}}^{\mathrm{pp}}$ and $W_{\mathrm{v}}^{\mathrm{pp}}$ contributions is 1.53 for $\mathrm{CHCl}_{3}, 1.45$ for $\mathrm{CH}_{2} \mathrm{Cl}_{2}$ and 1.29 for $\mathrm{CF}_{2} \mathrm{Cl}_{2}$. At constant density, contribution of phonon-rotational components $W_{\mathrm{v}}^{\mathrm{pr}}$ differ little in values, as compared with the isobaric case $W_{\mathrm{p}}^{\mathrm{pr}}$. The ratio of $W_{\mathrm{v}}^{\mathrm{pr}}$ to $W_{\mathrm{p}}^{\mathrm{pr}}$ is practically equal to 1 (within \pm 0.07 ), and independent of substances. This is in good agreement with the data cited in $[8,9]$ indicating a high degree of orientational ordering in solid $\mathrm{CHCl}_{3}, \mathrm{CH}_{2} \mathrm{Cl}_{2}$, and $\mathrm{CF}_{2} \mathrm{Cl}_{2}$ at the investigated temperatures.

The processes of phonon-phonon scattering in solid $\mathrm{CHCl}_{3}, \mathrm{CH}_{2} \mathrm{Cl}_{2}$ are a dominant source of thermal resistance. The additional contribution of a phononrotational component to the total thermal resistance of solid $\mathrm{CHCl}_{3}, \mathrm{CH}_{2} \mathrm{Cl}_{2}$ increases with temperature, and averages between $70 \%$ and $40 \%$ of a phonon-phonon component, at constant pressure. In solid $\mathrm{CF}_{2} \mathrm{Cl}_{2}$, the contributions of phonon-rotational and phonon-phonon interaction to the total thermal resistance are slightly (within the 20\%-limits) different by value from each other, in both isochoric and isobaric cases.
In Fig. 1(d), the ratios between phonon-phonon $W_{\mathrm{pp}}$ and phonon-rotational $W_{\mathrm{pr}}$ contributions to the total thermal resistance of solid $\mathrm{CHCl}_{3}, \mathrm{CH}_{2} \mathrm{Cl}_{2}$, and $\mathrm{CF}_{2} \mathrm{Cl}_{2}$ are shown. In all instances, the general tendency of the ratio $W_{\mathrm{pp}} / W_{\mathrm{pr}}$ is observed. In particular, both at constant pressure and constant volume, the ratio $W_{\mathrm{pp}} / W_{\mathrm{pr}}$ increases with temperature growth, which testifies that the growth of the phonon-phonon contribution to the total thermal resistance exceeds that of the phononrotational one. In the isobaric case, this excess is more substantial owing to thermal expansion. For instance, at constant pressure, the additional contribution associated with phonon-rotational interaction to the thermal resistance of solid $\mathrm{CHCl}_{3}$ amounts to $70 \%$ of the phononphonon component at $80 \mathrm{~K}$, and to about $40 \%$ at premelting temperatures. In the isochoric case, those values comprise $70 \%$ and $60 \%$, respectively.

\section{CONCLUSIONS}

On the basis of these studies it seems justified to conclude that in OO molecular crystals:

1. Discrepancies in behaviour of the temperature dependences of $\Lambda_{\mathrm{p}}$ and $\Lambda_{\mathrm{v}}$ are mainly governed by the intensity of phonon-phonon interaction, because phononrotational components depend on thermal expansion weakly.

2. In comparison with the isochoric case, the influence of thermal expansion is implemented as a more rapid growth of a phonon-phonon contribution to the total thermal resistance.

3. The temperature growth is accompanied by an increase in the ratio between a phonon-phonon and phonon-rotational component of total thermal resistance. In this case, thermal expansion causes a more substantial increase of the $W_{\mathrm{pp}} / W_{\mathrm{pr}}$.
[1] R. Berman, Thermal Conduction in Solids (Clarendon Press, Oxford, 1976).

[2] O. I. Pursky, N. N. Zholonko, V. A. Konstantinov, Fiz. Nizk. Temp. 29, 1021 (2003).

[3] O. A. Korolyuk, A. I. Krivchikov, I. V. Sharapova, O. O. Romantsova, Fiz. Nizk. Temp. 35, 380 (2009).

[4] X. Gao, Y. Nagasaka, A. Nagashima, Inter. J. Thermophys. 19, 415 (1998).

[5] A. I. Bondarenko, V. G. Manzhelii, V. A. Popov, M. A. Strzhemechny, V. A. Gavrilko, Fiz. Nizk. Temp. 8, 1215 (1982).

[6] D. G. Cahill, S. K. Watson, R. O. Pohl, Phys. Rev. B 46, 6131 (1992).

[7] V. B. Kokshenev, Yu. G. Kravchenko, I. N. Krupskii, Fiz.
Nizk. Temp. 11, 314 (1985).

[8] H. S. Gytowsky, D. N. McCall, J. Chem. Phys. 32, 548 (1966).

[9] L. M. LeBlanc, A. Anderson, J. Raman Spectrosc. 22, 255 (1991).

[10] I. N. Krupskii, V. G. Manzhelii, Sov. Phys. JETP 28, 1097 (1968).

[11] Table of Physical Values. Reference Book, edited by I. K. Kikoin (Atomizdat, Moscow, 1976) [in Russian].

[12] O. I. Pursky, V. A. Konstantinov, Fiz. Nizk. Temp. 33, 765 (2007) [Low Temp. Phys. 33, 584 (2007)].

[13] O. I. Pursky, V. A. Konstantinov, Eur. Phys. J. B 56, 205 (2007).

[14] O. I. Pursky, J. Phys. Stud. 9, 337 (2005). 


\title{
ВПЛИВ ТЕПЛОВОГО РОЗШИРЕННЯ НА ПРОЦЕСИ ПЕРЕНОСУ ТЕПЛА В ОРІЄНТАЦЙНО-УПОРЯДКОВАНИХ МОЛЕКУЛЯРНИХ КРИСТАЛАХ
}

\author{
О. І. Пурський ${ }^{1}$, В. О. Константінов ${ }^{2}$ \\ ${ }^{1}$ Київсъкий національний університет ім. Тараса Шевченка, фізичний факультет, \\ просп. Академіка Глушкова, 2, м. Київ, 03680, Украӥна \\ ${ }^{2}$ Фізико-технічний інститут низъких температур ім. Б. І. Веркіна НАН України, \\ просп. Леніна, 47, м. Харків, 61103, Україна
}

\begin{abstract}
Досліджено вплив теплового розширення на процеси переносу тепла в орієнтаційно-упорядкованих молекулярних кристалах. Для виділення внесків фонон-фононного та фонон-ротаційного розсіяння в повний тепловий опір при ізобарних та ізохорних умовах використано модифікований метод приведених координат. Показано, що відмінності в температурних залежностях ізобарної $\left(\Lambda_{\mathrm{p}}\right)$ та ізохорної $\left(\Lambda_{\mathrm{v}}\right)$ теплопровідності визначаються, головно, інтенсивністю фонон-фононної взаємодії, оскільки фонон-ротаційна компонента теплового опору майже не залежить від теплового розширення.
\end{abstract}

